\title{
O Moodle como mediador no processo de formação pedagógica: uma pesquisa- ação sobre a experiência de futuros professores em estágio extracurricular
}

Giséli Duarte Bastos - NTE - UFSM - giselibastos@gmail.com

Débora Marshall - NTE - UFSM - deboraeadufsm@ gmail.com

Greyce Arrua Storgatto - CCNE - UFSM - greycestorgatto@gmail.com

Letícia de Lima Borges - CE - UFSM - leti_lb@ hotmail.com

Edison Luiz Pavão Borges - CE/UAB - UFSM - edinhopavao@ hotmail.com

\section{Resumo}

Este trabalho objetivou investigar as contribuições de uma experiência envolvendo o Ambiente Virtual de Ensino-Aprendizagem Moodle na formação docente de estagiários, estudantes de Licenciatura, em estágio extracurricular, da Equipe Multidisciplinar do Núcleo de Tecnologia Educacional da Universidade Federal de Santa Maria. A metodologia foi pautada em uma pesquisa-ação, de abordagem qualitativa e teve como instrumento de coleta um questionário survey aplicado aos estagiários. Os dados demonstraram que aspectos advindos da experiência com as disciplinas construídas no AVEA, como fluência tecnológica, autonomia, diálogo e conhecimento pedagógico, foram considerados relevantes na formação docente pelos estagiários. Porém, tal ação também apresentou fragilidades, como a necessidade de articular a pesquisa ao processo, bem como esclarecer a teoria que embasa o Moodle e o trabalho envolvendo o Ambiente na Equipe Multidisciplinar. Assim, percebe-se que, ao explorar o Moodle, atentando para questões tecno-didático-pedagógicas das disciplinas nele construídas os estagiários puderam aprimorar e refletir sobre aspectos fundamentais às suas formações profissionais.

Palavras-chave: moodle, estágio extracurricular, formação de professores, equipe multidisciplinar.

\section{Teachers' formation mediated by LMS Moodle: an action research on initial teachers' experience in extra-curricular training}

\begin{abstract}
This paper seeks to examine the contributions of an experience with the LMS Moodle to trainee teachers' formation during extra-curricular training taking place in the Multidisciplinary Team of the Education Technology Center at the Federal University of Santa Maria. This study follows an action research methodology, within the domain of qualitative research. A survey questionnaire was employed to gather information from the trainees. The analysis of the data collected revealed that some outcomes ensued from the experience with teaching materials through the platform used in elearning courses, such as: fluency with technology, autonomy, dialogue and pedagogical content knowledge and skills, were considered by trainees as important to teachers' formation. On the other hand, there were some weak points related to this experience, for example: the need to join research with practice in the activities related to the teaching materials, as well as to focus on theoretical framework that guides teaching practices in Moodle. It must therefore be recognized that the exploitation of technical,
\end{abstract}


didactic and pedagogical aspects of teaching material and method when dealing with Moodle allowed trainees to reflect upon and develop essential issues concerning their professional formation.

Keywords: moodle, extra-curricular training, teachers' formation, multidisciplinary team.

\section{Introdução}

A educação necessita estar integrada às Tecnologias da Informação e da Comunicação (TIC) para acompanhar as constantes mudanças do (re)fazer humano e permitir a inclusão de educadores e educandos em um mundo cada vez mais conectado e tecnológico. Nesse sentido, cabe aos trabalhadores em educação refletirem e agirem em favor de uma prática educativa comprometida com a inclusão e a (trans)formação socioeducacional.

Tendo em vista essa realidade, a Universidade Federal de Santa Maria (UFSM), através do Decreto N. 021/2011, cria o Núcleo de Tecnologia Educacional (NTE) que tem por objetivo executar as políticas definidas pelas instâncias competentes da UFSM nas modalidades educacionais mediadas por tecnologias, atuando como agente de inovação dos processos de ensino-aprendizagem, bem como no fomento à incorporação das TIC aos projetos pedagógicos da UFSM. Tal atuação visa, principalmente, dar suporte e incentivar a utilização do Ambiente Virtual de Ensino-Aprendizagem (AVEA) Modular Object-Oriented Dynamic Learning Environment (Moodle), caracterizado como uma tecnologia educacional livre em rede, nas disciplinas de cursos da UFSM, proporcionando conhecimento e apropriação de formas de ensinar/aprender em rede, flexibilizando e diversificando o processo com opções de recursos e atividades educacionais.

A utilização de AVEA, como o Moodle, segundo Flores et al (2008 apud LISBÔA et al, 2009) marca um novo modelo de aprendizagem que ultrapassa o ensino tradicional reorientando-se para o construtivismo social ao promover um espaço de colaboração on-line e permitindo a construção coletiva do conhecimento, pelas oportunidades de partilha, comunicação, interação e promoção da autonomia. No entanto, o sucesso desta ferramenta depende, principalmente, do desenho estratégico criado pelo professor e da sua adequação ao público-alvo, ao contexto e aos objetivos que o envolve. A competência (tanto tecnológica quanto didático-pedagógica) e a confiança dos professores são fatores decisivos na implementação da inovação nas práticas educativas (PERALTA; COSTA, 2007).

Com base nesse contexto, existe no NTE a Equipe Multidisciplinar (EM) que, entre outras funções, realiza a Orientação Pedagógica (OP) dos materiais didáticos que compõem as disciplinas dos cursos de graduação e pós-graduação, na modalidade a distância da UFSM, elaboradas pelos docentes da Instituição. As orientações visam auxiliar os professores na busca de uma adequada estruturação das disciplinas no Moodle; a exploração e o conhecimento das potencialidades das ferramentas de recursos e de atividades de estudo disponíveis no AVEA; utilização rica e variada de recursos hipertextuais e multimídia; entre outras ações pertinentes ao uso do Ambiente. 
Nesse sentido, considerou-se a hipótese de envolver na tarefa de Orientação Pedagógica os Estagiários de Graduação (EG) que atuam na EM. Para esses estagiários, estudantes de Licenciatura, portanto, professores em formação, a tarefa seria parte de suas atividades de estágio extracurricular não-obrigatório. A participação dos EG na tarefa visa servir para o enriquecimento de suas formações docentes, principalmente, a partir do contato didático-pedagógico prático com o AVEA, além de capacitá-los quanto ao embasamento teórico de educação adotado pelo NTE. De acordo com Soares e Luciano (2004),

preparar os professores para a mudança de cultura necessária significa levá-los a conviver em ambientes onde isso possa estar ocorrendo e fazer com que eles possam observar e refletir sobre o próprio processo de interação e de transformação (SOARES; LUCIANO, 2004, p. 04).

Estudos (GIMENEZ; CRISTÓVÃO, 2004; LOPES; FEITOSA, 2011) destacam que a formação pedagógica prática nas licenciaturas deve permear todo o curso, desde seu início. Nessa perspectiva, o estágio extracurricular seria um espaço privilegiado para a formação pedagógica prática, a qual não deveria restringir-se apenas às práticas de ensino (ou Estágio Curricular Supervisionado).

Por estágio extracurricular entende-se o estágio realizado fora da sala de aula, em atividades não previstas nos programas de ensino das disciplinas da grade curricular, mas que podem ser consideradas como atividades acadêmico-científico-culturais, previstas na Resolução CNE/CP 2/2002. A busca por vivências que extrapolam a ordem do currículo se dá tanto na dimensão do ensino quanto na pesquisa e na extensão. No caso dos estudantes das licenciaturas, experiências com atividades didático-pedagógicas em contextos como, por exemplo, escolas, laboratórios de ensino, equipes multidisciplinares e projetos de extensão universitária podem ser valiosas para sua formação profissional.

Lopes e Feitosa (2011) relatam ações concretas vivenciadas em projetos multidisciplinares nos quais o estágio extracurricular configura-se como espaço de formação do futuro professor para uso das tecnologias. Os resultados desse estudo demonstram que alunos de cursos de licenciaturas específicas não estão dotados de formação que os prepare a fim de utilizar o computador (e seus recursos) para fins pedagógicos. Ainda, segundo os autores, as dificuldades detectadas pelos acadêmicos sugerem a necessidade de uma formação efetiva do professor que tem a Educação Básica como campo de atuação, no que diz respeito ao preparo para o uso das tecnologias atuais e o estágio extracurricular é um possível espaço para essa formação, ressalvadas as suas limitações.

Nesse viés, estudo de Gimenez e Cristóvão (2004), no contexto da formação de professores de Letras, demonstra que vários autores corroboram a ideia de que a flexibilização do currículo, por meio de estágios extracurriculares, por exemplo, possibilita avanços na formação que antecede a atuação profissional.

Sendo assim, o objetivo deste trabalho é investigar em que medida a utilização do Moodle para realização de atividades de apoio ao desenvolvimento de recursos didático-pedagógicos, durante o estágio extracurricular, colabora com a formação profissional docente dos estagiários de graduação da Equipe Multidisciplinar da Universidade Federal de Santa Maria. 


\section{Construções Metodológicas}

O trabalho foi desenvolvido na Universidade Federal de Santa Maria, Santa Maria, RS, Brasil, no Núcleo de Tecnologia Educacional a partir da Equipe Multidisciplinar (EM). Entre os trabalhos da EM, está a Orientação Pedagógica dos materiais didáticos que compõe as disciplinas dos cursos da UFSM na modalidade a distância, as quais são realizadas diretamente no AVEA Moodle. Tal tarefa é executada pelos Técnicos Administrativos em Educação do Cargo de Técnico em Assuntos Educacionais (TAE), com a supervisão do professor coordenador da EM e consiste em analisar as disciplinas montadas no Ambiente tendo em vista a exploração das potencialidades das ferramentas do AVEA, bem como a adequação didático-pedagógica de sua utilização.

Os EG da EM foram envolvidos diretamente na atividade e, para isso, receberam um roteiro com os principais elementos a serem observados nas disciplinas do Moodle, considerando: Estrutura (apresentação da disciplina, nome do professor e dos tutores, objetivos gerais e específicos, organização do conteúdo - unidades, subunidades, capítulos - metodologia, carga horária, cronograma das atividades com datas, avaliação, referências bibliográficas, plano de ensino, ementa da disciplina); Linguagem (que deve apresentar-se clara, precisa em tom conversacional/dialógico); Recursos (hipermídia, variedade de recursos); Atividades (problematizações e atividades permeando a disciplina, mescla de atividades colaborativas e individuais, correlação entre as atividades e os recursos, variedade de atividades). Os EG foram orientados pelos TAE a registrarem as observações, bem como refletirem sobre elas a fim de proporem sugestões de inovações e adequações aos docentes com vistas a colaborarem na construção das disciplinas.

Com base nisso, foi proposta uma pesquisa de abordagem qualitativa pautada em procedimentos técnicos de uma pesquisa-ação (GIL, 1991), considerando como sujeitos os três estagiários da EM, em estágio extracurricular não-obrigatório, estudantes de Licenciaturas em Química, Pedagogia a Distância e Educação Especial na UFSM. O instrumento de coleta de dados adotado foi um questionário tipo survey aplicado durante o mês de abril de 2012 pelos TAE, contendo 15 questões fechadas, porém com possibilidade de inserção de comentários (Quadro 1). As questões foram elaboradas a fim de investigar a relação entre as práticas adotadas durante a realização das orientações pedagógicas no Moodle e o disposto nas Diretrizes Curriculares Nacionais (DCN) para a Formação de Professores da Educação Básica, em nível superior, curso de licenciatura, de graduação plena, instituídas pela RESOLUÇÃO CNE/CP N ${ }^{\circ} 1$, de 18 de Fevereiro de 2002.

Quadro 1 - Questionário tipo survey aplicado com os estágios de graduação da Equipe Multidisciplinar NTE/UFSM para identificar relação entre a realização de orientações pedagógicas no Moodle e o perfil esperado de um profissional Licenciado. 
Responda as questões seguintes de acordo com sua impressão, enquanto estagiário de graduação da Equipe Multidisciplinar, considerando sua atuação na tarefa de orientação pedagógica $(\mathrm{OP})$ dos materiais didáticos elaborados e disponibilizados no Ambiente Moodle.

Tendo em vista os aspectos esperados na formação docente, você considera que a atividade de OP, através do Moodle, contribuiu para:

\section{Questões}

1) O conhecimento sobre tecnologias da informação e 9) Uma prática desenvolvida com ênfase nos procedimentos da comunicação de observação e reflexão, com o registro das observações realizadas

2) $\mathrm{O}$ uso de metodologias, estratégias e materiais de 10) O desenvolvimento de competências referentes ao apoio inovadores domínio do conhecimento pedagógico

3) $\mathrm{O}$ uso de diferentes tipos de recursos pedagógicos e 11) O desenvolvimento de competências referentes ao de fontes de pesquisa teórica gerenciamento do próprio desenvolvimento profissional

4) A interação e a comunicação através do diálogo 12) $\mathrm{O}$ exercício de atividades de enriquecimento cultural

5) $\mathrm{O}$ desenvolvimento de autonomia intelectual

13) A identificação de uma relação entre a teoria abordada e um possível uso dela na futura prática docente

6) O desenvolvimento de hábitos de colaboração e de 14) A aprendizagem como processo de construção de trabalho em equipe. conhecimentos, habilidades e valores em interação com a realidade, no qual as capacidades pessoais são colocadas em uso

7) O conhecimento de práticas de pesquisa que 15) A resolução de prováveis situações-problema a serem permitam o aperfeiçoamento da enfrentados na futura atuação docente

prática pedagógica

8) O desenvolvimento de competências referentes ao conhecimento de processos de investigação que possibilitem o aperfeiçoamento da prática pedagógica

De acordo com as DCN, foram considerados aspectos como: o uso das TIC, conhecimento pedagógico, diálogo, enriquecimento cultural, conhecimento e aprimoramento de práticas investigativas, reflexão sobre a prática, aprendizagem colaborativa, autonomia e resolução de situações problema. Para cada afirmação o estagiário precisou escolher uma opção entre: discordo completamente, discordo em parte, não concordo nem discordo, concordo em parte ou concordo plenamente e, se julgasse relevante, poderia inserir um comentário que justificasse a sua escolha. $\mathrm{O}$ questionário foi elaborado no Moodle e configurado para que cada participante pudesse respondê-lo apenas uma vez.

\section{Resultados e Discussão}

Na sequência, são analisados os apontamentos gerados e percebidos através da aplicação do questionário com os estagiários de graduação da Equipe Multidisciplinar, antes disso, sistematizou-se os resultados na Figura 1.

Figura 1- Representação gráfica dos resultados do questionário aplicado aos estagiários de graduação da Equipe Multidisciplinar NTE/UFSM. 


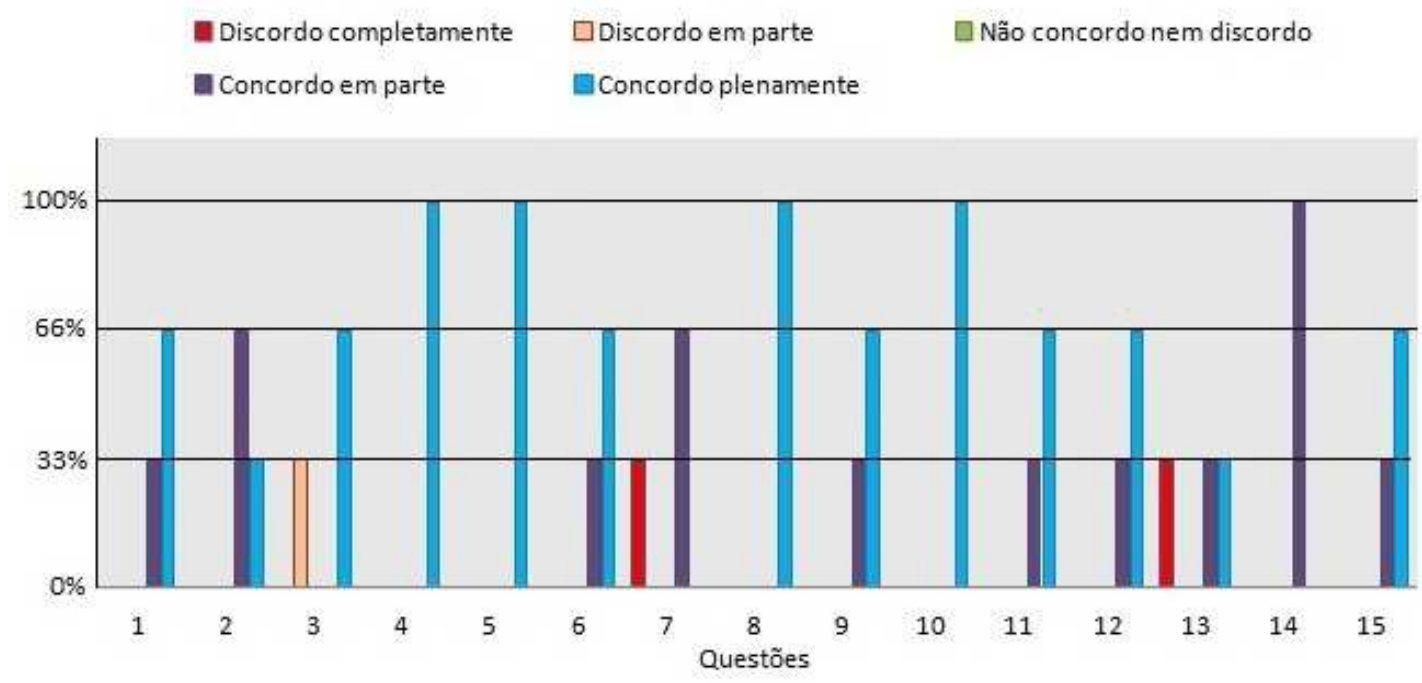

Sobre a Afirmativa 1, que trata da contribuição da tarefa realizada pelos EG para seu conhecimento sobre TIC, $66 \%$ deles concordam plenamente, e $33 \%$ concordam em parte, enquanto que em relação à Afirmativa 2, 66\% dos EG concordam em parte, e $33 \%$ concordam plenamente que a tarefa de OP colaborou em sua formação para o uso de metodologias, estratégias e materiais de apoio inovadores. Com isso, percebemos que o papel do Moodle na atividade foi considerado relevante pelos estagiários e o contato com o AVEA, certamente, contribui para a familiarização com as TIC, porém ações de capacitações tecno-didático-pedagógicas que possibilitem os EG desenvolverem fluência quanto à utilização das ferramentas e das potencialidades hipermidiáticas do ambiente tornam-se necessárias para que os futuros professores percebam e construam estratégias inovadoras em suas atuações docentes. Essa perspectiva está de acordo com Karsenti, Villeneuve e Raby (2008) ao afirmarem que estudantes de licenciatura preparados para o uso pedagógico das tecnologias têm mais chances de integrá-las à sua prática posteriormente.

Para a Afirmativa 3, referente à contribuição da tarefa de OP para o uso de diferentes tipos de recursos pedagógicos e de fontes de pesquisa teórica, $66 \%$ deles responderam que concordam plenamente, e 33\% que discordam em parte. Percebe-se que é necessário estimular a utilização variada de fontes de pesquisa teórica pelos EG que embasem de forma consistente os apontamentos feitos aos docentes no Moodle. A participação deles nas atividades de pesquisa para desenvolvimento de tecnologia educacional e recursos educacionais no Moodle, que são desenvolvidas na EM, também torna-se fundamental pois, tendo conhecimento mais profundo sobre tais recursos, a sua utilização e a adoção de hábitos de pesquisa na prática docente torna-se facilitada.

Em relação às Afirmativas 4 e 5, 100\% dos EG concordam plenamente que a tarefa de OP através do Moodle contribuiu para o desenvolvimento da interação e da comunicação baseada no diálogo e também para o desenvolvimento da autonomia intelectual. É provável que tal concordância seja consequência da "atmosfera" dialógica promovida pelos TAE ao interagirem e estimularem o diálogo entre os sujeitos, tanto pessoalmente, quanto através do AVEA. Essa prática está de acordo com Freire (2005) 
ao afirmar que o "diálogo é essencial na educação", independente da modalidade, e "somente o diálogo, que implica em pensar crítico, é capaz, também, de gerá-lo. Sem ele não há comunicação e sem esta não há verdadeira educação" (FREIRE, 2005, p. 96). Através do diálogo, respeita-se as concepções de mundo dos sujeitos que dialogam e leva-se à autonomia. (FREIRE, 1997).

Nessa perspectiva, a Afirmativa 6 considera o desenvolvimento de hábitos de colaboração e de trabalho em equipe, com a qual 33\% dos EG concordam em parte e 66\% concordam plenamente. De acordo com Duarte (2001 apud ABERTI, 2011), o papel do outro é fundamental no desenvolvimento e na aprendizagem. A aprendizagem em colaboração não anula, mas destaca a participação criadora do aluno, o seu desenvolvimento intelectual e sua capacidade de discernimento. Com isso, embora um dos EG não esteja plenamente de acordo em relação a essa questão, o Estagiário 1 diz: Concordo plenamente, porque a partir deste trabalho de OP nos vimos em situações em que a colaboração e o rendimento andaram juntos. Enquanto encontrávamos dúvidas ao analisar determinado material, houve mútua ajuda e assim conseguimos respeitar prazos. Tal afirmação reflete as ações presenciais entre os estagiários, os TAE e os docentes na EM, mas ainda não reflete o real papel da colaboração via Moodle. Sendo assim, torna-se necessário trazer problematizações aos EG, que debatam a concepção sócio-construtivista que embasa o desenvolvimento do Moodle. Essas discussões poderão contribuir para o aprimoramento dos apontamentos feitos aos docentes nas OP na busca de uma maior exploração das ferramentas de atividades colaborativas do Moodle, por exemplo. Ainda, poderá servir de base para a incorporação de práticas colaborativas na atuação profissional dos futuros professores considerando que:

as plataformas colaborativas oferecem uma oportunidade de desenvolvimento de uma nova perspectiva de ensino-aprendizagem orientada, não somente para a disponibilização e transmissão de conteúdos, mas para os contextos de produção colaborativa de conteúdos científico-tecnológicos no âmbito dos processos colaborativos dialógico-problematizadores em rede (ABEGG et al, 2010, p. 164).

Na Afirmativa 7, 66\% dos EG concordam em parte, enquanto 33\% discordam completamente que a tarefa em que se envolveram proporcionou conhecimento de práticas de pesquisa que permitam o aperfeiçoamento da prática pedagógica. Esses dados indicam a necessidade de incluir a pesquisa no processo de realização das OP mediadas pelo Moodle. De acordo com o Estagiário 1: Obtive, neste trabalho, o conhecimento referente ao aperfeiçoamento da prática pedagógica (pensando em minha formação profissional, inclusive), mas não foi através de pesquisas. Tais apontamentos estão sendo, em parte, problematizados e refletidos a começar pela realização da presente pesquisa que poderá contribuir para o aperfeiçoamento das práticas adotadas tanto pela própria EM quanto pelos futuros professores. Nesse sentido, fazendo referência também à afirmativa 5 (que trata sobre a autonomia), no afã de promover a autonomia intelectual do estudante e do professor, Güllich (2007, p.4) adota a perspectiva do Educar pela Pesquisa na Escola. De acordo com essa perspectiva, o ensino-aprendizagem ocorre através da pesquisa, como princípio do processo de produção de conhecimentos. Essa concepção de educação desenvolve a autonomia intelectual do estudante, que vai agir como sujeito ativo de sua aprendizagem e adquirir 
a autonomia social de cidadão crítico frente à realidade. Certamente essa perspectiva, que pode ser mediada por tecnologias como o Moodle, pode inspirar práticas educacionais que tenham como objetivo o desenvolvimento de autonomia pela pesquisa pelos futuros professores.

O formato metodológico que baliza as tarefas na EM é a ação-reflexão-ação. Esse formato pode proporcionar aos EG o desenvolvimento das habilidades de observação, sistematização, análise e interpretação de dados coletados. É exatamente sobre essa questão que trata a Afirmativa 8 do questionário. Nesse item, 100\% dos EG concordam plenamente que a tarefa de OP através do Moodle contribuiu para o desenvolvimento de competências referentes ao conhecimento de processos de investigação que possibilitam o aperfeiçoamento da prática pedagógica. Cabe ressaltar que um dos EG já se encontra em fase de prática de ensino, no estágio curricular supervisionado, o que proporciona a ele condições de refletir sobre os dois diferentes contextos de estágio e tentar promover a articulação das diferentes práticas. Esse trabalho corresponde a um processo de ação-reflexão-ação em que o futuro professor assume papel de protagonista ativo de sua formação prática pedagógica. É fundamental que o professor no exercício da docência esteja preparado para a imprescindível e constante (re)formulação da práxis. Para tanto, é preciso enriquecer o trabalho pedagógico por meio da capacitação, atualização e aperfeiçoamento de professores, problematizando a necessidade de flexibilidade de métodos e critérios, disponibilizando as possibilidades de colaboração, interação e interatividade que as TIC propiciam, através das diversas linguagens (verbal, visual, hipertextual, audiovisual e de hipermídia) para oportunizar o desenvolvimento de metodologias inovadoras. Essa capacitação deve ser propiciada não só em nível de formação inicial, mas também para a formação continuada.

A Afirmativa 9 trata da possibilidade de exercer uma prática com destaque para a observação e a reflexão, seguidas de registro. A esse respeito, $66 \%$ dos EG concordam plenamente e $33 \%$ concordam em parte. É importante destacar que, durante o processo de orientação pedagógica no AVEA, os EG puderam realizar dois procedimentos complementares: a observação e a reflexão sobre o uso do Moodle nas disciplinas dos cursos de graduação da UFSM como mediador do processo de conhecimento. $\mathrm{O}$ Estagiário 1 comenta que: "Foi necessário um procedimento de observação e reflexão muito minucioso ao analisar cada material didático. $O$ registro foi feito tendo como base o roteiro e o preenchimento de seus itens." Tais elementos correspondem ao roteiro disponibilizado aos estagiários e descrito na metodologia deste trabalho.

Um dos pontos centrais destacados nesse processo foi a gradual autonomia do EG ao propor sugestões aos docentes, decorrente da possibilidade de desenvolvimento de competências referentes ao domínio do conhecimento pedagógico - tema da Afirmativa 10, com a qual $100 \%$ dos EG concordam plenamente. Um dos aspectos positivos verificados nessa pesquisa é o fato de que os primeiros registros dos roteiros escritos pelos EG e revisados pelos TAE apontavam certo receio deles na indicação aos docentes de uso de ferramentas do Moodle. Com o decorrer das orientações elaboradas a partir do contato com o AVEA e do feed-back dos TAE, percebeu-se uma maior segurança nas sugestões. Nesse sentido, é interessante pontuar que o acompanhamento do processo, por meio da mediação desenvolvida pelos TAE, gerou o que Vygostsky (1998) chama de "zona de desenvolvimento proximal", ou seja, a antecipação de 
conhecimentos que, sem a interação com parceiros mais experientes, demorariam mais tempo para serem construídos. Tais apontamentos também estão de acordo com o discutido na Afirmativa 6 sobre o desenvolvimento de hábitos de colaboração.

Diante da Afirmativa 11, 66\% dos EG concordam plenamente que houve o desenvolvimento de competências referentes ao gerenciamento do próprio desenvolvimento profissional, sendo que 33\% concordam em parte. A esse respeito, o Estagiário 1 enfatiza: Acredito que foi um passo inicial para o desenvolvimento destas competências, mas ainda será preciso exercitá-las em outras atividades de OP para definir o termo "gerenciamento". Já o Estagiário 2 acredita que: Como Estagiária da EM e participante das Orientações Pedagógicas, acredito ter adquirido um grande embasamento acerca de diferentes possibilidades de atuação docente, que certamente servirão como alicerce para minha futura "prática-pedagógica". Assim, é visível que, apesar de ser passível de aprimoramento, no que tange ao gerenciamento da própria formação, tendo em vista o fato de ter sido uma primeira experiência, percebe-se que há, no processo de orientação pedagógica no Moodle realizado pelos EG, interessantes potencialidades para reflexão e (re)composição de saberes interessantes à sua constituição como docente. A própria participação nessa pesquisa criou condições para que os EG pudessem verificar em que medida houve (ou não) movimentos de transformação em si mesmos advindos dessa tarefa no Moodle.

Além da contribuição para a prática pedagógica do futuro professor, a orientação pedagógica, abriu ao EG a necessidade de mobilizar um leque de conhecimentos que transcendem suas áreas de formação inicial, haja vista o contato, no Moodle, com disciplinas de diferentes cursos e áreas de conhecimento. Nesse sentido, a Afirmativa 12 reitera o exercício de atividades de enriquecimento cultural, a qual $66 \%$ dos EG concordam plenamente e $33 \%$ concordam em parte. Para o Estagiário 1: Como não envolveu pesquisa bibliográfica propriamente dita, creio que a questão do enriquecimento cultural fique em torno do conhecimento de diferentes disciplinas e seus conteúdos, mas apenas um breve olhar ao conteúdo em si.

Nessa pesquisa, ficou evidente um aspecto a ser melhorado em futuras ações de orientação pedagógica envolvendo os EG na EM: a identificação de uma relação entre a teoria abordada e um possível uso dela na futura prática docente - foco da Afirmativa 13. Percebeu-se, a partir do dado que $33 \%$ concordam plenamente, $33 \%$ concordam em parte e $33 \%$ discordam completamente, que é preciso mais clareza dos estudos teóricos que embasam os trabalhos da EM, visto as discrepâncias entre as marcações dos EG. Como exemplo, temos o comentário do Estagiário 1: Particularmente, a princípio não me baseei em uma teoria propriamente dita. Utilizei do olhar crítico com relação à presença, coerência e mescla de atividades e recursos dentro da disciplina. Dessa forma, é notável a necessidade de investir com mais afinco nesses estudos - já citados na Introdução - para as próximas experiências de uso da orientação pedagógica no Moodle como processo formativo para os EG.

No tocante à Afirmativa 14, que discorre sobre a aprendizagem como processo de construção de conhecimentos, habilidades e valores em interação com a realidade, no qual as capacidades pessoais são colocadas em uso, 100\% dos EG concordam em parte. Vale ressaltar o que destaca o Estagiário 3: as Orientações Pedagógicas possibilitaram pra mim um olhar peculiar, crítico e reflexivo sobre o processo de construção de conhecimentos. Pois, não basta somente inovar pedagogicamente, com recursos 
hipermidiáticos e com tecnologia inovadora, é necessário também que a didática e metodologia sejam inovadas, analisadas e construídas com uma finalidade educacional de ensino e aprendizagem. Nesse sentido, percebemos o quanto os EG puderam efetuar uma reflexão crítica sobre o Moodle e suas possibilidades pedagógicas, entendendo-o para além de um repositório de materiais didáticos, mas como um espaço em potencial para a sensibilização do estudante a partir de linguagens hipertextuais e hipermidiáticas, desde que conectadas ao diálogo problematizador como fio condutor do processo de ensino-aprendizagem.

Sobre a resolução de prováveis situações-problema a serem enfrentados na futura atuação docente - objeto de atenção da Afirmativa 15 - 66\% dos EG concordam plenamente, $33 \%$ concordam em parte. O Estagiário 2, comenta sua impressão: $A$ identificação que fiz e que posso considerar como uma possibilidade em minha futura prática docente é a ideia de construção de um ambiente educativo que respeite as peculiaridades dos educandos, com atividades colaborativas que facilitem o processo de ensino-aprendizagem. Sendo assim, é interessante notar que o contato com o Moodle, a partir do olhar, seja como docente (no planejamento das atividades e sua sistematização no Moodle), seja como estudante (ao deparar-se com aquela organização), incentivou os EG a refletirem com mais propriedade sobre os elementos que compõem um Ambiente Virtual de Ensino Aprendizagem e suas possíveis aplicações na futura atuação profissional.

\section{Considerações finais}

A investigação acerca do papel do Moodle como mediador do processo de formação pedagógica prática de estagiários de graduação em estágio extracurricular proporcionou importantes reflexões sobre a utilização pedagógica do Ambiente e a preparação dos futuros professores para incorporarem as tecnologias em suas práticas docentes.

Através de procedimentos de pesquisa-ação e a aplicação do questionário survey, encontrou-se resultados que sugerem a necessidade de engajar os estagiários nas atividades de pesquisa para desenvolvimento de tecnologia educacional e recursos educacionais no Moodle. Prática e pesquisa, de acordo com o arcabouço teórico que orienta as ações na EM, implicam-se e são indissociáveis. Nesse viés, é preciso fomentar, entre os EG, a adoção de hábitos de pesquisa, que os acompanharão ao longo de sua prática profissional como professores. Os resultados também apontam para a necessidade de ações de capacitação tecno-didático-pedagógica dos EG em Moodle uma vez que o desenvolvimento de metodologias inovadoras em suas práticas educacionais é favorecido pela fluência técnica com as ferramentas do AVEA e do conhecimento das potencialidades hipermidiáticas que o ambiente oferece.

Outro aspecto que pode ser re-elaborado nas ações da EM para contribuir com a formação docente dos EG é a relação entre os pressupostos teóricos que fundamentam as práticas pedagógicas e os procedimentos metodológicos que dão suporte a elas. Somente a partir de um embasamento teórico consistente é possível gerar ações educacionais que favoreçam uma aprendizagem significativa e contextualizada. Nesse sentido, a concepção teórico-metodológica por trás do Moodle pode inspirar práticas 
educacionais que promovam o desenvolvimento de competências que articulem habilidades, valores e atitudes relacionados a: autonomia intelecto-social, colaboração, reflexão crítica frente aos conteúdos e à realidade.

Sendo assim, o Moodle - com base nas possibilidades de comunicação e colaboração em rede mediadas pelo diálogo entre os sujeitos, na integração de diversas linguagens (hipertextual, audiovisual, hipermidiática), na interatividade e na interação permitidas pelo ambiente - pode contribuir com a formação docente para $o$ desenvolvimento de metodologias e materiais de apoio inovadores que incluam, de forma crítica, estudantes e professores no mundo atual.

\section{Referências}

ABEGG, I.; DE BASTOS, F. P.; MÜLLER, F. M.; FRANCO, S. R. K. Aprendizagem Colaborativa em rede mediada pelo wiki do Moodle. Educar em Revista, UFPR, Curitiba, n. 38, set./dez. 2010. Disponível em: 〈http://ojs.c3sl.ufpr.br/ojs2/index.php/educar larticle/viewFile/13129/13530>. Acesso em: 13 abr. 2012.

ALBERTI, T. F. Das possibilidades da formação de professores a distância: um estudo na perspectiva da teoria da atividade. Tese (Doutorado em Educação). Programa de Pós-Graduação em Educação da Universidade Federal do Rio Grande do Sul- UFRGS, Porto Alegre, 2011.

BRASIL/Ministério da Educação, Conselho Nacional de Educação. Resolução CNE/CP 1, de 18 de fevereiro de 2002. Institui Diretrizes Curriculares Nacionais para a Formação de Professores da Educação Básica, em nível superior, Curso de Licenciatura, de graduação plena. Brasília, 2002.

BRASIL/Ministério da Educação, Conselho Nacional de Educação. Resolução CNE/CP 2, de 19 de setembro de 2002. Institui a duração e a carga horária dos cursos de licenciatura, de graduação plena, de formação de professores da Educação Básica em nível superior. Brasília, 2002.

FREIRE, P. Pedagogia da autonomia: saberes necessários à prática educativa. 6 . ed. Rio de Janeiro: Paz e Terra, 1997.

. Pedagogia do oprimido. 46. ed. Rio de Janeiro: Paz e Terra, 2005.

GIL, A. C. Como elaborar projetos de Pesquisa. São Paulo, Atlas, 1

GIMENEZ, T.; CRISTOVÃO, V. L. L. Derrubando paredes e construindo pontes: formação de professores de inglês na atualidade. Revista Brasileira de Linguística Aplicada, v. 5, n. 2, p. 85-95, 2004. Disponível em <http://www.periodicos.letras.ufmg.br/ index.php/rbla/article/view/768>. Acesso em: 20.abr 2012.

GÜLLICH, R. I. da C. Educar pela pesquisa: processos de estudo aprendizagem com pesquisa. Revista Setrem. Três de Maio, n 8, ano V, p. 54-60, jan/jun. 2006.

KARSENTI, T.; VILLENEUVE, S.; RABY C. O uso pedagógico das Tecnologias da Informação e da Comunicação na formação dos futuros docentes no Quebec. Educação e Sociedade, Campinas, v. 29, n. 104, p. 865-889, out. 2008.

LISBÔA, E. S.; DE JESUS, A. G.; VARELA, A. M. L. M.; TEIXEIRA, H. S.; COUTINHO, C. P. LMS em contexto escolar: estudo sobre o uso da Moodle pelos docentes de duas escolas do Norte de Portugal. Revista Educação, Formação e Tecnologia. Universidade do Minho. Portugal, 2009. Disponível em: 


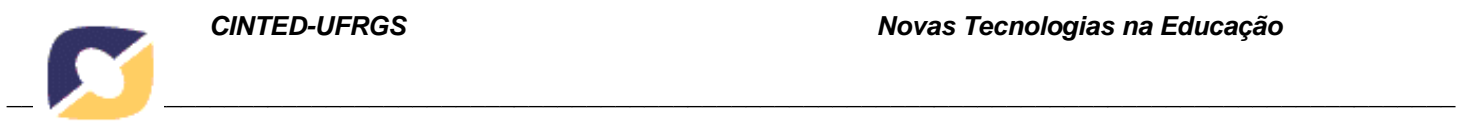

12

<http://repositorium.sdum.uminho.pt/bitstream/1822/9428/1/52.pdf $>$. Acesso em: 21 abr. 2012.

LOPES, R.; FEITOSA, E. Estágio extracurricular como um possível espaço de formação do professor para uso de tecnologias. Revista Ciência em Extensão. v.7, p.144, 2011. Disponível em:

http://ojs.unesp.br/index.php/revista_proex/article/view/467>. Acesso em: 21 abr. 2012. PERALTA, H.; COSTA, F. Competência e confiança dos professores no uso das TIC. Síntese de um estudo internacional. Sísifo. Revista de Ciências da Educação, 3, pp. 77-86, Portugal, 2007. Disponível em: $\langle$ http://sisifo.fpce.ul.pt $>$. Acesso em: 22 abr. 2012.

SOARES, E. M. S.; LUCIANO, N. A. Formação continuada de professores no contexto das tecnologias digitais. Disponível em: < http://www.abed.org.br/congresso2004/por/htm/016-TCA2.htm>Acessoem:15abr.2012. UNIVERSIDADE FEDERAL DE Santa Maria. Resolução N. 002/04, de 30 de janeiro de 2004. Dispõe sobre a regulamentação da Educação a Distância na Universidade Federal de Santa Maria e dá outras providências. Santa Maria, 2004.

VYGOTSKI, L. S. Pensamento e Linguagem. Tradução: Jefferson Luiz Camargo. São Paulo: Martins Fontes, 1998. 